\title{
Flow Induced Vibration (FIV) Research of Oil and Gas Process Piping System
}

\author{
M F I Ahmad Fuad, N Lukman, A D Z Ahmad Nazari
}

\begin{abstract}
Piping systems in crude oil production facilities tend to handle high pressure and high velocity flowing fluid at certain flow rate limit resulted in generation of turbulence flow. This turbulence can generate high levels of broad band kinetic energy which can propagate through the system. Even though the energy is distributed across a wide frequency range, most of the excitation is concentrated at low frequency (typically below $100 \mathrm{~Hz})$; the lower the frequency, the higher the level of excitation from turbulence. This leads to excitation of the low frequency vibration modes of the pipe work, in many cases causing visible motion of the pipe and, in some cases, the pipe supports, and this phenomenon is called Flow induced vibration (FIV) and if excessive can result in fatigue failure. This objective of the paper is to identify potential sources of FIV on piping by predicting the Likelihood of failure (LOF) and advising on the necessity for system modifications to minimize or eliminate any FIV induced piping or line failure from Flow Induced Turbulence. These are done by conducting a FIV assessment for piping systems in oil production facilities which are potentially affected by vibration due to both process conditions and mechanically induced pipework vibration. Another scope of this paper is to apply the recommendation action required in order to reduce the likelihood of failure by changing pipe diameter and/or wall thickness by looking at the fluid structure interaction (FSI). By changing the outer diameter and the wall thickness of the pipe, the formation of the excitation in flow regime and the presence of the critical flow disturbance will decrease. These changes are able to reduce the formation of FIV thus increasing the lifespan of the piping system.
\end{abstract}

Index Terms: Excitation. Fatigue, Flow Induced Vibration, Piping System

\section{INTRODUCTION}

Piping fatigue failure due to excessive piping vibration is a major cause of machinery downtime, leaks, excessive noise, explosions and fires in refineries and petrochemical plants [1]. Due to the potential dangers associated with this type of failure, it is a major concern to engineers. Excessive vibration levels typically occur when the natural mechanical frequency of the piping system is excited by a pulsation or mechanical source [1]. If fracture occurs, the sudden release of a hazardous or flammable pressurized fluid can be extremely hazardous to health as well as having

Revised Manuscript Received on August 19, 2019.

M F I Ahmad Fuad, Oil and Gas Engineering, Faculty of Chemical Engineering, Universiti Teknologi Mara, Shah Alam, Malaysia.(email: fazrilirfan@uitm.edu.my )

N Lukman, Oil and Gas Engineering, Faculty of Chemical Engineering, Universiti Teknologi Mara, Shah Alam, Malaysia. Malaysia. environmental consequences. The financial costs involved in the loss of

production, corrective action, litigation and any resulting penalties which may arise from fatigue failure can be extensive. In addition to this, the potential for negative publicity and loss of life cannot be dismissed.

Turbulence will exist in most piping systems encountered in practice. In straight pipes it is generated by the turbulent boundary layer at the pipe wall, the severity of which depends upon the flow regime as defined by Reynolds number. However, for most cases experienced in practice the dominant sources of turbulence are major flow discontinuities in the system. Typical examples are process equipment, partially closed valves, short radius or bends, tees or expanders. This turbulence can generate high levels of broad band kinetic energy which can propagate through the system. Although the energy is distributed across a wide frequency range, most of the excitation is concentrated at low frequency (typically below $100 \mathrm{~Hz}$ ); the lower the frequency, the higher the level of excitation from turbulence. This leads to excitation of the low frequency vibration modes of the pipe work, in many cases causing visible motion of the pipe and, in some cases, the pipe supports, and this phenomenon is called Flow Induced Vibration (FIV).

If the piping system is not properly designed, this excitation would lead to piping component fatigue failure. It has been reported that more than $20 \%$ of the piping failures in the UK sector of the North Sea were due to piping vibration and fatigue failures [2]. In 1974, an error in the piping system in a petrochemical plant resulted in an explosion which caused more than USD 114 million in damages. In nuclear reactors, over 80 cases of ruptures or leaks were identified in the pressurized water system to the pump load over a two-year period [1]. Piping vibration is a serious risk since a single pipe-work failure can shut down a facility for hours or even weeks, resulting in lost production at the very least [3]. Consequently, it is essential for the oil and gas industry that vibration issues are considered at the design stage.

The study focused on piping systems that convey high pressure and temperature fluid flow from upstream choke valve to production header. The system consists of various types of pipe fitting such as reduced pipe, Tee type, and ball valve. The scopes of this study including the evaluation of the outcome of the FIV assessments against the acceptance

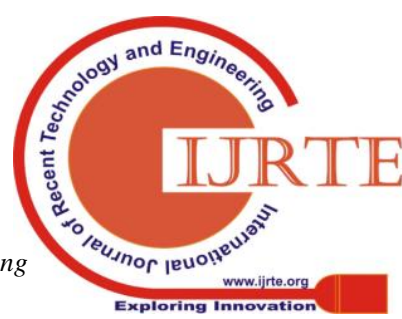


criteria and recommend suitable measures for any lines that do not meet the acceptability. The recommended action on the failure piping part in this case changing the outer diameter of the pipe and wall thickness was simulated in computational fluid dynamics software and identified the effectiveness of the action by generating flow pattern to observe the generation of turbulent energy.

\section{FLOW INDUCED VIBRATION (FIV) ANALYSIS \& RESULTS}

\section{A. Likelihood of Failure Determination}

The assessment methodology adapts a two-stage approach; screening and detailed analyses. All the data were gathered from process flow diagram (PFD), piping and instrumentation diagram (P\&ID), and piping material class specification. A few regulation and standard were used in this study as a reference in term of the piping specification, pipe schedule, and safe limitation requirement. The piping dimensions in Steel Pipe Dimension-ANSI Schedule 80 requirement were used as the reference to choose the new dimension of the pipes that had failed to meet the safe requirement during detailed analysis. Multiple assumptions were made in this study; 1) all piping is in "flexible" (worst case scenario) stiffness regime, 2) The piping structure that connected to the piping support system is assumed effectively rigid and 3) The calculations have been made using the assumptions that mass flow rate and velocity are constant downstream of each device.

As for the first step, more than 25 lines pipe from the crude oil piping system underwent the first screening to analyze the condition of the lines by filtering out low risk lines before proceeds to FIV detailed analysis. This analysis was done to identify the potential failure occurs due to the flow turbulence in the piping. It was done by calculate the momentum $\rho v 2$ (kg/ms2) using fluid density and fluid velocity. Process fluid with a $\rho v 2$ less than 5000 is classified as having low risk. Process fluid with a $\rho v 2$ between 5000 to 20000 is classified as having medium risk whereas process fluid with a $\rho v 2$ more than 20000 is judged as having risk [3][8]. Lines which failed FIV qualitative screening analysis will be subjected to the FIV detailed analysis. In this study, 25 lines pipe were failed FIV qualitative screening analysis and need to proceed to FIV detailed analysis.

Second step, FIV detailed analysis determine the actual LOF which takes into account the piping flexibility and restraints by using the actual pipe span length from isometric drawings. LOF was calculated resulted from relationship of kinetic energy, fluid viscosity factor and also the flow induced vibration factor. The safe LOF limit of the pipe shall be below than 0.3 , if exceed need to undergo further detailed analysis. LOF was calculated by taking into consideration of the kinetic energy $\rho v 2$ of the fluid as per equation (1-4). $\rho v 2$ is determined by using fluid density and fluid velocity. Among these 25-line pipes, only 5 lines pass the safe limit as defined by the Energy Institute [3] which is, LOF below than 0.3 . The first screening result was simplified as shown in Figure 1.
Pipe Internal Area $\left.(A), m^{2}=[[\mathrm{OD}-(2 \mathrm{xT}))]^{2} / 4\right] \times$ PI

Where OD is pipe outer diameter in meter, $\mathrm{T}$ is pipe thickness in meter and PI values is 3.142

Velocity inside the pipe $(\mathrm{V}), \mathrm{m} / \mathrm{s}, \mathrm{V}=\rho^{-1} \times \mathrm{Q} \times \mathrm{A}^{-1}$ (2)

Where ${ }^{\rho}$ is density in $\mathrm{kg} / \mathrm{m}^{3}, \mathrm{Q}$ is mass flow rate, $\mathrm{kg} / \mathrm{s}$ and A is pipe internal area in $\mathrm{m}^{2}$.

Kinetic Energy (KE), $\mathrm{kg} / \mathrm{ms}^{2} \quad \mathrm{KE}=\rho v^{2}$

Where ${ }^{P}$ is density in $\mathrm{kg} / \mathrm{m}^{3}$ and $\mathrm{V}$ is velocity in $\mathrm{m} / \mathrm{s}^{2}$

Likelihood of Failure $(\mathrm{LOF})=\left(\rho v^{2} / \mathrm{Fv}\right) \times \mathrm{FVF}$

Where FVF is fluid viscosity factor and $\mathrm{V}$ is velocity in $\mathrm{m} / \mathrm{s} 2, \mathrm{Fv}$ is flow induced vibration factor and $\rho \mathrm{v} 2$ is Kinetic Energy in $\mathrm{kg} / \mathrm{ms} 2$. Note that $\mathrm{FVF}=1.0$ for liquid and multiphase fluids.

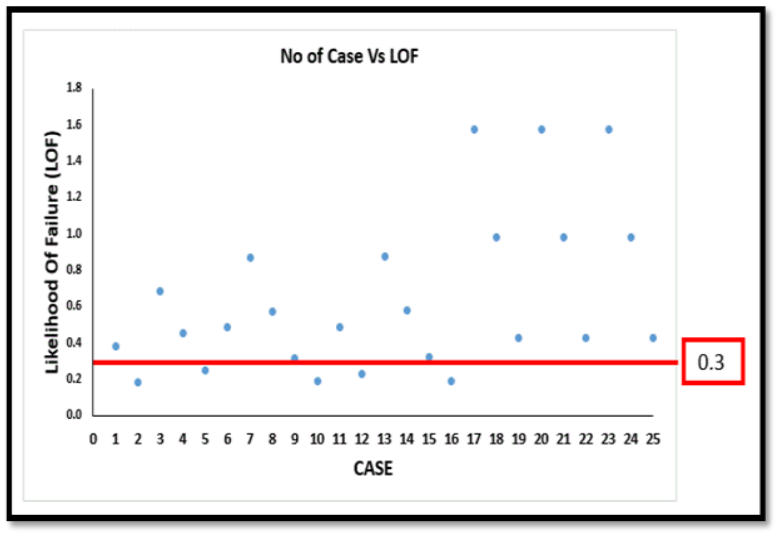

Fig. 1. Number of Cases versus LOF

For lines that score $\mathrm{LOF} \geq 0.3$, reparative action step should be applied to improve piping integrity. The EI Guidelines offer several options to achieve a reduction in LOF. The line pipe is considered acceptable and no action required if the $\mathrm{LOF}<0.3$. If the $\mathrm{LOF}$ fall between 0.3 and 0.5 , a visual study ought to be attempted to check for poor development/geometry/support for the primary line. Modifications to main line are not required and small bore connection actions should be undertaken. If the calculated LOF is between 0.5 to 1.0 , a visual study ought to be attempted to check for poor development/geometry/support for the primary line. Main Line should be redesigned or re-supported for relevant piping as far as practicable. SBC actions shall be undertaken. If LOF is more than 1 , a visual study should be done to identify the poor construction and support for the main line. If LOF cannot be reduced to less than 1 through changing the stiffness regime alone, the alternative options are to reduce the flow rate or increase pipe size/wall thickness [3].

For further detailed analysis, 1 line that failed the screening was used for this study. This line is connected from choke valve to the production header and supported by 2 pipe supports. The total length of the piping is approximately 14.7 m (48 feet) and the material of the pipe used was Duplex Stainless Steel with schedule 80 . The production phase that flowing through the pipe was identified as a multiphase fluid (oil and gas). The sample configuration of the piping

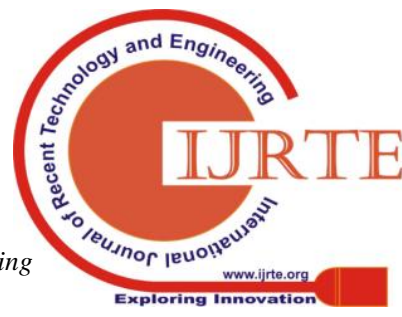


system is shown in Figure 2.

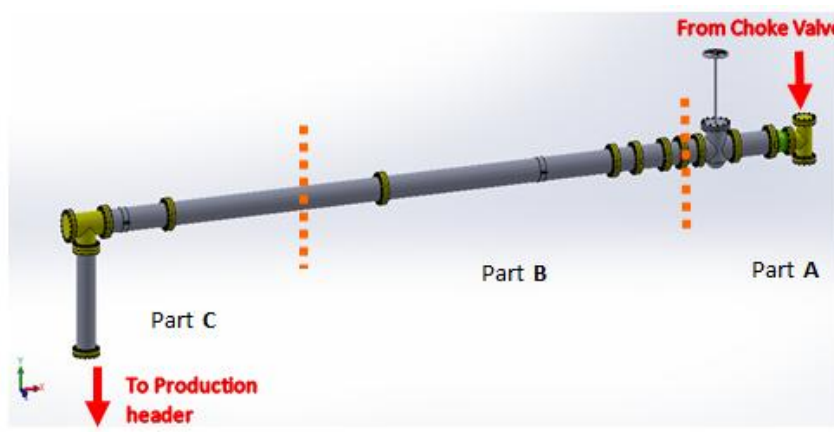

Fig. 2. Configuration of Piping System

The configuration is divided into 3 main sections which are section $\mathrm{A}, \mathrm{B}$, and $\mathrm{C}$ due to the properties of mixture flow inside the pipe is difference. The pipe support arrangement is such that the piping sections are in the flexible regime. The characteristic of the flow inside the pipe can be simplified as shown in Table 1 below.

Table 1. Piping Specification and Parameters

\begin{tabular}{|c|c|c|c|c|c|c|}
\hline & 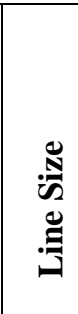 & $\begin{array}{l}\quad \text { Pip } \\
\text { e } \\
\text { outer } \\
\text { diam } \\
\text { eter } \\
\quad(m \\
\text { m) }\end{array}$ & $\begin{array}{l}\quad \text { Wal } \\
\text { l } \\
\text { thickn } \\
\text { ess } \\
\quad(m \\
\text { m) }\end{array}$ & $\begin{array}{l}2^{p v} \\
/ \mathrm{m} . \mathrm{kg} 2 \\
)^{2}\end{array}$ & $\begin{array}{c}\mathbf{L} \\
\text { OF }\end{array}$ & Action \\
\hline A & $00^{3}$ & $.9^{323}$ & $2^{17.4}$ & $\begin{array}{c}77 \\
38.77\end{array}$ & $\begin{array}{r}0 . \\
6865\end{array}$ & \begin{tabular}{l}
\multicolumn{1}{c}{ Failed, } \\
proceed to \\
Detailed \\
Analysis
\end{tabular} \\
\hline B & $00^{3}$ & $.9^{323}$ & $2^{17.4}$ & $\begin{array}{c}60 \\
27.34\end{array}$ & $\begin{array}{r}0 . \\
8686\end{array}$ & \begin{tabular}{l}
\multicolumn{1}{c}{ Failed, } \\
proceed to \\
Detailed \\
Analysis
\end{tabular} \\
\hline C & $50^{2}$ & $.9^{323}$ & $2^{17.4}$ & $\begin{array}{r}73 \\
03.89\end{array}$ & $\begin{array}{r}0 . \\
8788\end{array}$ & \begin{tabular}{l}
\multicolumn{1}{c}{ Failed, } \\
proceed to \\
Detailed \\
Analysis
\end{tabular} \\
\hline
\end{tabular}

FIV Screening analysis was done to identify the potential failure occurs due to the flow turbulence in the piping. The safe limit of the pipe shall be below than 0.3 , if exceed need to undergo further detailed analysis. All analyzed sections; A, B and $C$ have exceeded the safe LOF criteria which are 0.6865 , 0.8686 and 0.8788 respectively and are subject to further detailed analysis. Since the LOF of sections more than safe requirement which is 0.3 , for this study, section A pipe as shown in Figure 3 to Figure 5 was selected for further corrective action. A few recommendation actions are considered for this study such as reducing mass flow rate (mitigation at source), increase pipe nominal diameter (mitigation at path), increase pipe wall thickness (mitigation at path) and introduce pipe support, thereby altering the stiffness regime and natural frequency of the piping section (mitigation at path). To reduce LOF, pipe diameter and wall thickness were changed according to the Steel Pipe Dimensions - ASME B31.3 Process Piping [4] and the new calculated LOF as per Table 2.

Table 2. New LOF of Piping System of Section A

\begin{tabular}{|c|c|c|c|}
\hline $\begin{array}{c}\text { Pipe } \\
\text { Outer } \\
\text { Diame } \\
\text { ter } \\
\text { (m } \\
\text { m) }\end{array}$ & $\begin{array}{c}\text { Wall } \\
\text { Thickne } \\
\text { Ss }\end{array}$ & $\begin{array}{c}\text { Screening } \\
\text { Likelihood of } \\
\text { Failure, LOF }\end{array}$ & Action \\
\hline 323. & 17.42 & 0.6885 & $\begin{array}{l}\text { Main Line } \\
\text { should be } \\
\text { redesigned. }\end{array}$ \\
\hline 355. & 19.05 & 0.4535 & $\begin{array}{l}\text { Modificati } \\
\text { on on Main } \\
\text { Line not } \\
\text { required but } \\
\text { visual survey } \\
\text { should be } \\
\text { undertaken. }\end{array}$ \\
\hline 406. & 21.44 & 0.2510 & $\begin{array}{l}\text { Acceptable } \\
\text { No action } \\
\text { required }\end{array}$ \\
\hline
\end{tabular}

\section{B. Flow Simulation and Characterization}

To verify the result from the calculation of the likelihood of failure, the flow simulation is done do determine the presence of turbulence that can lead to flow induced vibration in the piping system. The inlet volumetric flow and outlet volumetric flow are set at $0.2035 \mathrm{~m}^{3} / \mathrm{s}$ and $0.7693 \mathrm{~m}^{3} / \mathrm{s}$ respectively. The result is generated in term of turbulent energy. The Figure 3 shows the condition of pipe with outer diameter $323.9 \mathrm{~mm}$ and $17.42 \mathrm{~mm}$ wall thickness. While Figure 4 and 5 show the condition inside the pipe of 355.6 $\mathrm{mm}$ and $406.4 \mathrm{~mm}$ outer diameter respectively

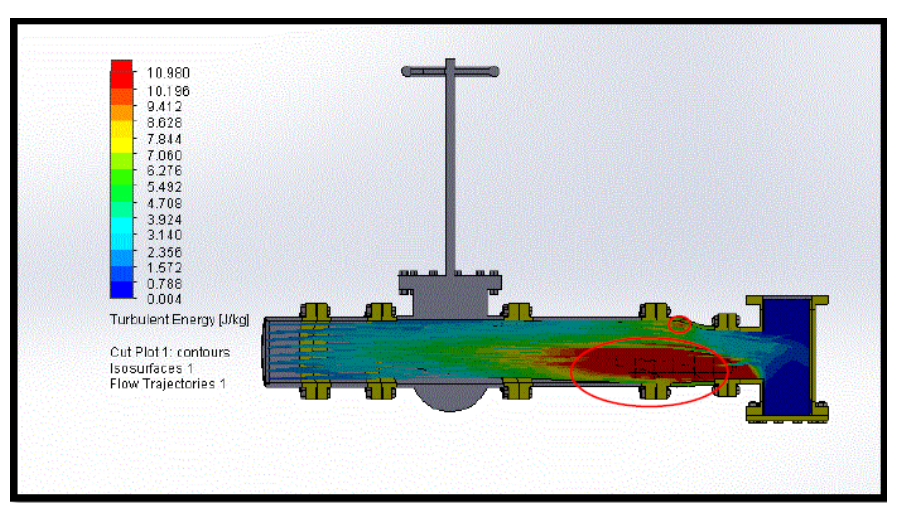

Fig. 3. Flow characteristic of $323.9 \mathrm{~mm}$ outer 


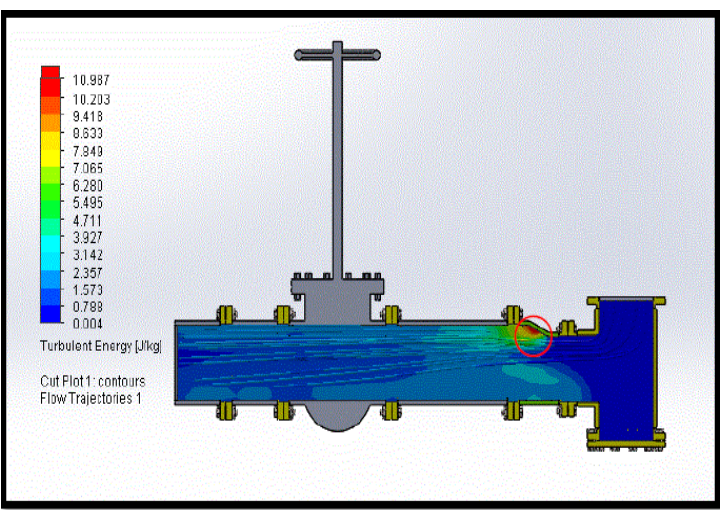

Fig. 4. Flow characteristic of $355.6 \mathrm{~mm}$ outer diameter.

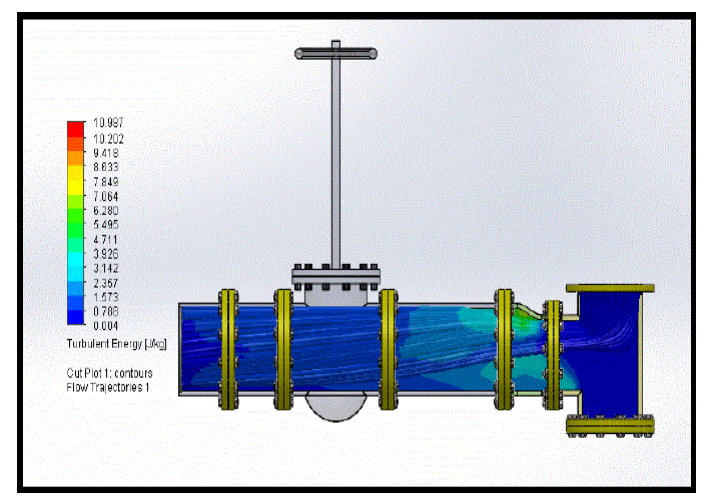

Fig. 5. Flow characteristic of $\mathbf{4 0 6 . 4} \mathbf{m m}$ outer diameter

The critical and high reading of turbulence energy detected at the $12 \times 10$ INS reducer pipe, and at connecting flange between reducer and $636 \mathrm{~mm}$ pipe. This is because of in turbulent flow; the relative motion of the fluid in the boundary layer generated flow disturbances in the form of vortices or eddies. As the volumetric flow increase inside the pipe so does to the amount of the turbulence. There is continuous transfer of energy from the large eddies into smaller eddies, which will dissipate most of the energy. This kinetic dissipation produces large kinetic energy losses in the fluid. As the fluid molecule in the vortices go from locations of high kinetic energy to low kinetic energy, the kinetic energy of the fluid will be converted into the potential energy in form of pressure. The pressure fluctuation will excite vibratory oscillations in the pipe through which the fluid is flowing. The movement of the pipe also causes additional pressure fluctuations in return. This two-way interaction may result in flow induced vibration.

As a corrective action, the larger outer diameter of pipe and thicker wall thickness is replaced. All the mixture properties are maintained the same. As the outer diameter of the pipe and wall thickness increase, the formations of the critical turbulence energy gradually decrease. This is verified that, by increasing the outer diameter of the pipe, the interactions between the mixtures flow and pipe structure is successful reduced.

\section{ConClusion}

This study deals with the screening analysis and computational analysis of flow-induced vibration in the piping system, focusing more on oil and gas industry. The modal analysis in the pipe flow configuration was studied to verify the accuracy the changes physical properties of the pipe in term of the outer diameter size and wall thickness towards the formation of excessive vibration in the piping system. To address the piping integrity risk due to vibration, facility operator requires implementing the Condition Based Monitoring (CBM) Vibration Assessment. These can benefit employees, managers, operations staff, shareholders, and society as a whole. The benefit includes, increase in safety aspect, reduce environmental risk and reduce overall operational risk. This assessment might be not totally accurate with the real situation in oil and gas industry due to some limitation, such as lack of time to do proper analysis and limited in the capability of the software to verify the effect of the variables accurately. However, it still contributes to estimating the occurrence of the failure in the future.

\section{ACKNOWLEDGMENT}

This work is supported via financial fund namely the LESTARI GRANT: 600-IRMI/MYRA 5/3/LESTARI (0084/2016) managed by Research Management Centre, Universiti Teknologi MARA, Shah Alam, Malaysia.

\section{REFERENCES}

1. Wachel, J.C., Morton, S.J. \& Atkins, K.E., Piping Vibration Analysis 19th TurboMachinery Symposium. (1990) pp.119-34

2. Bruce, R.D., Bommer, A.S. \& LePage, T.E : Solving Acoustic Induced Vibration Problems in Design Stage. Sound and Vibration. (2013) pp.8-11

3. Energy Institute: Guideline for the Avoidance of Vibration Induced Fatigue Failure in Process Pipework. London: Energy Institute The Energy Institute, London (2008)

4. ASME B31.3: Process Piping, ASME Code for Pressure Piping (2016)

5. ASME B31.8: Gas Transmission and Distribution Piping Systems (2003)

6. Ong Zhi Caho, Wen Tong Chong, Zubaidah Ismail, Siamak Noroozi Failure analysis of flow induced vibration problem of in-serviced duplex stainless steel piping system in oil and gas industry. Research Gate, 18(6), (2014) 417-422

7. D,Princelin Noel. Design of gas pipes an analysis of flow induced vibration. International Journal of Innovative Trends and Emerging Technologies. 1(1), (2014) 1-7

8. M. Siba, W. Wanmahmood, M. Zaki, R. Rasani, M. Nassir Flow-induced vibration in pipes: Challenges and Solutions - A review: Journal of Engineering Science and Technology Vol. 11, No. 3 (2016) 362 - 382 (2016)

9. N.E Ligterink, R. Groot, E. Gharaibah, H.J. Slot: Flow induced vibration of subsea gas production systems caused by choke valves: SPE Annual Technical Conference and Exhibition (2012), pp4662-4672

10. R Veerapandi, G Karthikeyan, G.R Jinu, \& Kannaiah, R.: Experimental Study and analysis of flow induced vibration in a pipeline. International Journal of Engineering Research and Technology (IJERT), 3(5), (2014) 1996-1999.

11. Hou, J. Tan, H Li: Flow-induced vibration in the compressible cavity flow. Vibroengineering PROCEDIA, (2017) Vol. 14, 2017, p. 238-243.

12. R. A. Khabibullin, E. V. Zhigalev, A. V. Trifonov, A. V. Pyatkin, K. A Goridko, A. R. Shabonas, V. S. Verbitsky, Flow induced vibration analysis of multiphase pipeline of Novoportovskoye field. Oil Industry Journal, OnePetro, (2017) Vol. 12, p.56-59 